\title{
Static analysis of Concrete Pouring Robot Arm based on Ansys Workbench
}

\author{
Hao Shuai, Qi Yuming \\ Institute of Robotics and Intellgent Equipment \\ Tianjin University of Technology and Education \\ Tianjin, China
}

\begin{abstract}
Mechanical arm is an important actuator of concrete pouring robot, its performance determines the stability of the concrete pouring robot using, so you need to analysis whether it can fully meet the requirements of engineering. Use Solidworks software to establish a model of concrete pouring robot arm, and using the finite element analysis software Ansys Workbench statics analysis was carried out on the mechanical arm, get the stress and strain diagram of mechanical arm, and the hinge point connection mode of mechanical arm optimization design.
\end{abstract}

Keywords-Concrete pouring robot arm, Statics analysis, Ansys Workbench, optimization design

\section{INTRODUCTION}

Concrete pouring robot, as a kind of special operation mobile robot, is widely used in the field of building construction with its highly intelligent automatic pouring and self-diagnosis. In order to ensure that the mechanical arm can transport the concrete evenly and accurately to the designated casting position, it is necessary to carry out statics analysis. At present, many mechanical structures have undergone the process from design to statics analysis to optimization design, and have been continuously verified in the process of use, thus achieving the most stable state. The current finite element analysis has been accepted by more and more engineers and designers as a widely used mechanical structure analysis method in the current engineering field.

Static analysis is the basis of mechanical design. In this paper, considering the gravity, concrete pouring robot conveying basic load, pipe due to the weight of traction, wind load and lateral force of the dynamic load, the static analysis of the mechanical arm. Finally, the stress and strain diagrams of the mechanical arm are obtained. By analyzing the force condition of the mechanical arm and combining with the actual working conditions, the structure is optimized and designed so that the mechanical arm can further meet the requirements of the casting robot in the complex working conditions.

\section{ESTABLISHMENT OF CONCRETE POURING ROBOT MODEL}

By measuring the concrete pouring robot used in the construction process, the relevant data of the mechanical arm are shown in table 1 and table 2. With of Solidworks software, using feature modeling method, draw the turntable mechanical arm, single section, cylinder, connecting rod, in the process of establishing model should be considered to parameter changes, connection of each hinge point, the position of the hinge point hole, hinge points hole size, at the same time should also note that each section of the mechanical arm interface shape. Finally, assemble the parts and import the established $3 \mathrm{~d}$ model into Ansys Workbench.

TABLE I. BASIC PARAMETERS OF ROBOT

\begin{tabular}{|c|c|c|c|}
\hline $\begin{array}{c}\text { Arm section } \\
\text { number }\end{array}$ & $\begin{array}{c}\text { Height of } \\
\text { pouring }(\mathrm{m})\end{array}$ & $\begin{array}{c}\text { Radius of } \\
\text { pouring(m) }\end{array}$ & Folding way \\
\hline 4 & 36.6 & 32.6 & C-shape \\
\hline
\end{tabular}

TABLE II. BASic Parameters of Mechanical ARm

\begin{tabular}{|c|c|c|}
\hline Mechanical arm & Length(mm) & Angle $\left(^{\circ}\right)$ \\
\hline Mechanical arm 1 & 8860 & 94 \\
\hline Mechanical arm 2 & 7960 & 180 \\
\hline Mechanical arm 3 & 7960 & 180 \\
\hline Mechanical arm 4 & 7855 & 230 \\
\hline
\end{tabular}

The connecting rod structure between each mechanical arm is a variation mechanism of a single cylinder six hinged point. According to the actual construction demand, the mechanical arm used in this paper selects the upper fulcrum $\mathrm{C}$ - shaped winding mode shown in Figure 1. The changing oil cylinder drives the connecting rod of the three hinge points, and drives the two-force rod action. Thus, the relative rotation of the secondary mechanical arm is realized. Other mechanical arms are connected in the same way.

This paper is supported by

the National Key Technology R\&D Program(2015BAK06B04);

the key technologies $R \& D$ program of Tianjin(13ZCZDGX01500,

14ZCZDSF00022,15ZXZNGX00260). 


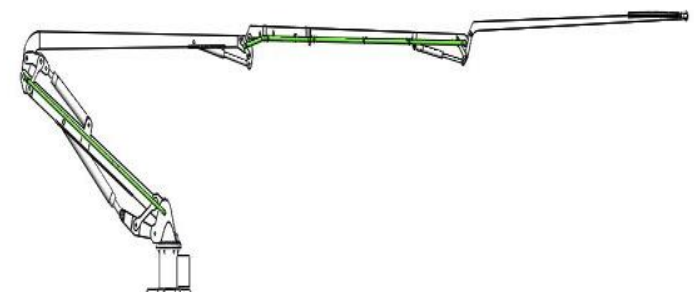

Fig. 1. The model of concrete pouring robot arm

$$
\text { Fig. } 2 .
$$

\section{ADD METERIAL PROPERTIES AND PARTITION GRIDS}

When using Ansys Workbench for finite element analysis of the mechanical arm, First need to add the material properties of the model .we choose 43430 alloy steel, the material has the advantages of light weight, good welding characteristics, clean and tidy appearance, It can meet the need of engineering, the mechanical properties of the material are shown in table 3 .

TABLE III. PARAMETERS OF MECHANICAL ARM MATERIAL

\begin{tabular}{|c|c|c|c|c|}
\hline $\begin{array}{c}\text { Tensile } \\
\text { strength } \\
(\mathrm{MPa})\end{array}$ & $\begin{array}{c}\text { Yield } \\
\text { strength } \\
(\mathrm{MPa})\end{array}$ & $\begin{array}{c}\text { Density }(\mathrm{kg} / \\
\left.\mathrm{mm}^{3}\right)\end{array}$ & $\begin{array}{c}\text { Elastic } \\
\text { Modulus } \\
(\mathrm{MPa})\end{array}$ & $\begin{array}{c}\text { Poisson } \\
\text { ratio }\end{array}$ \\
\hline 740 & 710 & $7.85 \times 10^{-6}$ & $2.1 \times 10^{5}$ & 0.32 \\
\hline
\end{tabular}

In Ansys Workbench, grid division is of great significance for the later statics solution. In the Workbench provides five methods: Automatic, MultiZone , sweep, Tetrahedrons, Hex Dominant. When the grid is divided, we need to consider the contradiction between the cost and the number of copies of the fine mesh, the grid can make the results more accurate, but will increase the CPU computing time and storage space, especially some unnecessary details will greatly increase the demand analysis, so we must choose the appropriate mode of mesh.

In this analysis, automatic was used, and "Element Midside Nodes" was set to "keep", "Relevance Center" was set to "Coarse", "Smoothing" was set to "Medium", and "Transition" was set to "Fast".

\section{LOAD ANALYSIS AND STATICS ANALTSIS OF THE MECHANICAL ARM}

When the arm is all unfolded, it can be regarded as a cantilever beam with a variable cross-section. This is one of the most dangerous conditions, as shown in Figure 2. Analyze the working state of the mechanical arm. According to the different of working situation concrete pouring robot mechanical arm is on the complex and changeable load. In the actual work environment, the mechanical arm bears the basic load of gravity and the weight of the pipe. At the same time, it will be subjected to dynamic loads such as traction, wind load and lateral force.

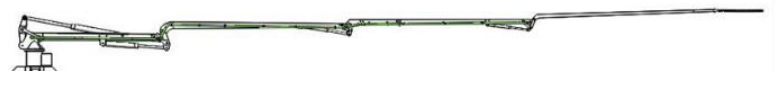

Fig. 3. horizontal extension of concrete pouring robot arm

During construction, the mechanical arm is affected by dynamic load. The dynamic load is mainly caused by the impact of high pressure cement on the conveying pipe and the wind load, which will eventually be transformed into the moment action on each arm frame and hinge point of the mechanical arm. After calculation, the self-bending moment of the four parts of the mechanical arm are,399.2KN $\bullet \mathrm{m}, 262.1$ $\mathrm{KN} \bullet \mathrm{m}, 77 \mathrm{KN} \bullet \mathrm{m}$ and $39.4 \mathrm{KN} \bullet \mathrm{m}$. The dynamic load wind bending moment are $406 \mathrm{KN} \bullet \mathrm{m}, 464 \mathrm{KN} \bullet \mathrm{m}, 197 \mathrm{KN} \bullet \mathrm{m}$ and $55.8 \mathrm{KN} \cdot \mathrm{m}$. The bending moments of inertia force are 251.3 $\mathrm{KN} \cdot \mathrm{m}, 105 \mathrm{KN} \bullet \mathrm{m}, 39.2 \mathrm{KN} \cdot \mathrm{m}$ and $10.7 \mathrm{KN} \cdot \mathrm{m}$. These loads are added to the static analysis module of Ansys Workbench, which can be obtained as follows: Add these loads to the static analysis module of Ansys Workbench, and the stress strain diagram as shown in figure 3 and figure 4 can be obtained:

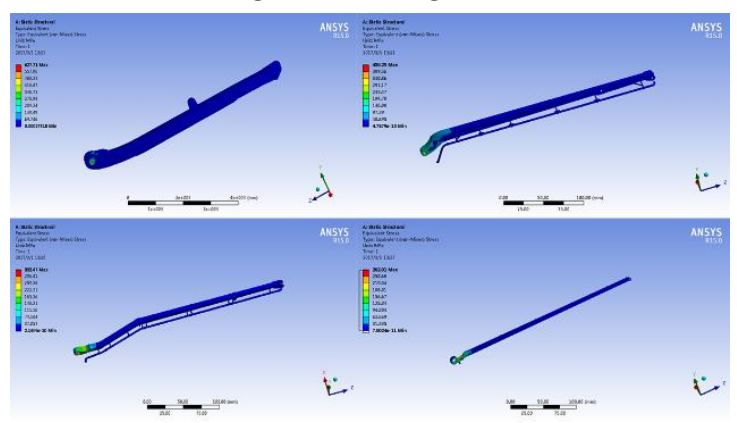

Fig. 4. stress nephogram

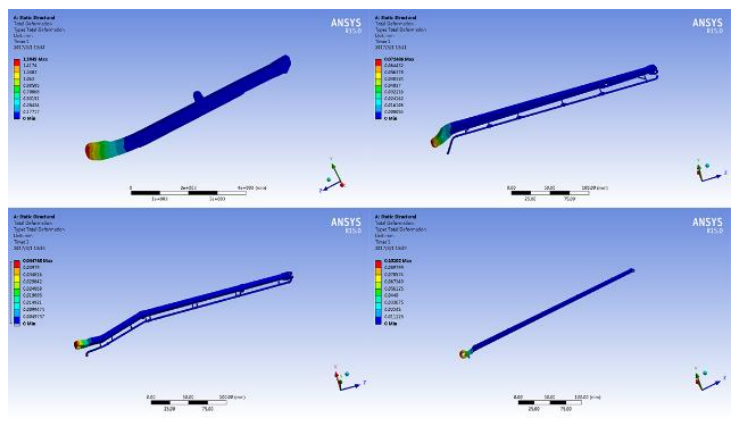

Fig. 5. Strain Nephogram

\section{OPTIMAL DESIGN}

From the results of the finite element analysis, it can be seen that the maximum stress of the mechanical arm is 627.71MPa, which appears at the hinge point of the first stage arm connecting rod. The steel of the mechanical arm is 4340 alloy steel treated by normalizing, and its yield limit is $710 \mathrm{MPa}$, which is welded into a graded box beam. The maximum stress on other arms also appears on the articulated pin hole position. The reason for the high articulation stress is: first, the flat steel plate suddenly has a notch; second, the pin shaft will pass the load of other arms, so there will be great 
stress. If you can change the form of the gap on the steel plate and change the position of the pin shaft on the mechanical arm, the stress value of each joint can be reduced. The optimization of the arm is optimized by the method of optimizing the first stage arm hinge connection. The results of the optimization are shown in Figure 5.

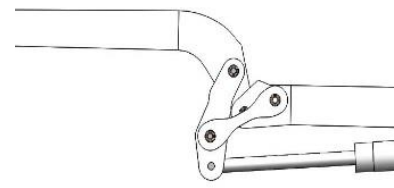

(1)

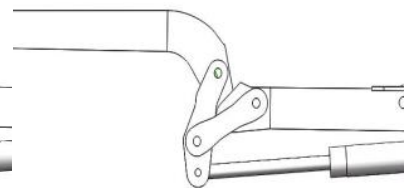

(2)
Fig. 6. Hinge point optimization comparison diagram 6:

The stress analysis after optimization is shown in figure

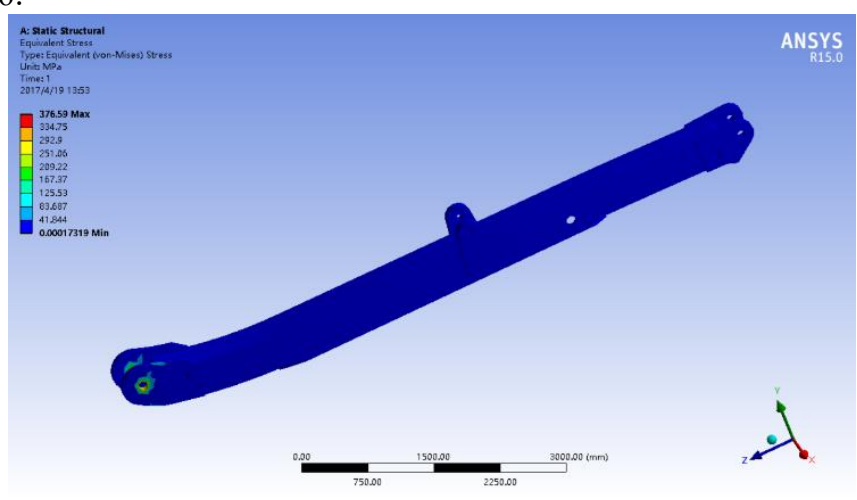

Fig. 7. Optimized stress analysis diagram

\section{CONCLUTIONS}

The static analysis of concrete pouring robot arm by Ansys Workbench software, seen from the stress and strain diagram, structure of mechanical arm in the maximum stress location in the hinge point, and an arm hinge point has the maximum stress is $627.71 \mathrm{MPa}$, close to the material yield limit of $710 \mathrm{MPa}$, so we use optimization method of hinge point connection mode to optimize the design of the arm, the optimized stress reduced to $376.59 \mathrm{MPa}$. It has to meet the requirements of concrete robot.

\section{REFERENCES}

[1] Fan B H, Jiao H . Statics analysis of EOD robot manipulator based on Workbench Ansys(J).Manufacturing Automation, 2014, 4:34-36

[2] Deng S P ,Peng J H . Finite element analysis and structural optimization of hydraulic fracturing mechanical arm of concrete $(\mathrm{J})$. Manufacturing Automation, 2015, 23:61-63

[3] Yuan A F ,Wang A L. Modeling and optimization design of 6-dof welding robot based on Solidworks and ANSYS Workbench $(J)$. Mechanical Transmission, 2013, 2: 53-57 